\title{
Manejo de abscesos profundos del cuello con sistema VAC
}

\author{
Management of deep neck abscesses with VAC
}

Rebeca Cordero G. ${ }^{1}$, Irania Blanco G. ${ }^{1}$ y Carlos Jiménez J. ${ }^{1}$

Se trata de 2 pacientes hospitalizados en el segundo trimestre de 2018 en el Servicio de Cirugía Hospital San José, con abscesos cervicales, el primero corresponde a paciente esquizofrénico con absceso en cara anterolateral derecha con extenso tejido esfacelado, exposición de tráquea y ángulo mandibular (Figura 1), siendo manejado con aseos seriados en pabellón, manejo de vía aérea en unidad de cuidados críticos, e instalación de sistema $\mathrm{VAC}^{\mathrm{B}}$ (Kinetic Concepts Inc, San Antonio Texas, EE.UU.). Egresa luego de 41 días y es controlado en consulta con evolución satisfactoria sin necesidad de cierre con sutura adicional (Figura 2).

El segundo caso corresponde a paciente diabético con absceso cervical posterior con abundante tejido necrótico (Figura 3), cultivo positivo para
'Servicio de Cirugía Hospita San José. Santiago, Chile.

Recibido 2020-07-21 y aceptado 2020-08-04

Correspondencia a: Dra. Rebeca Cordero G. rbkcordero@gmail.com

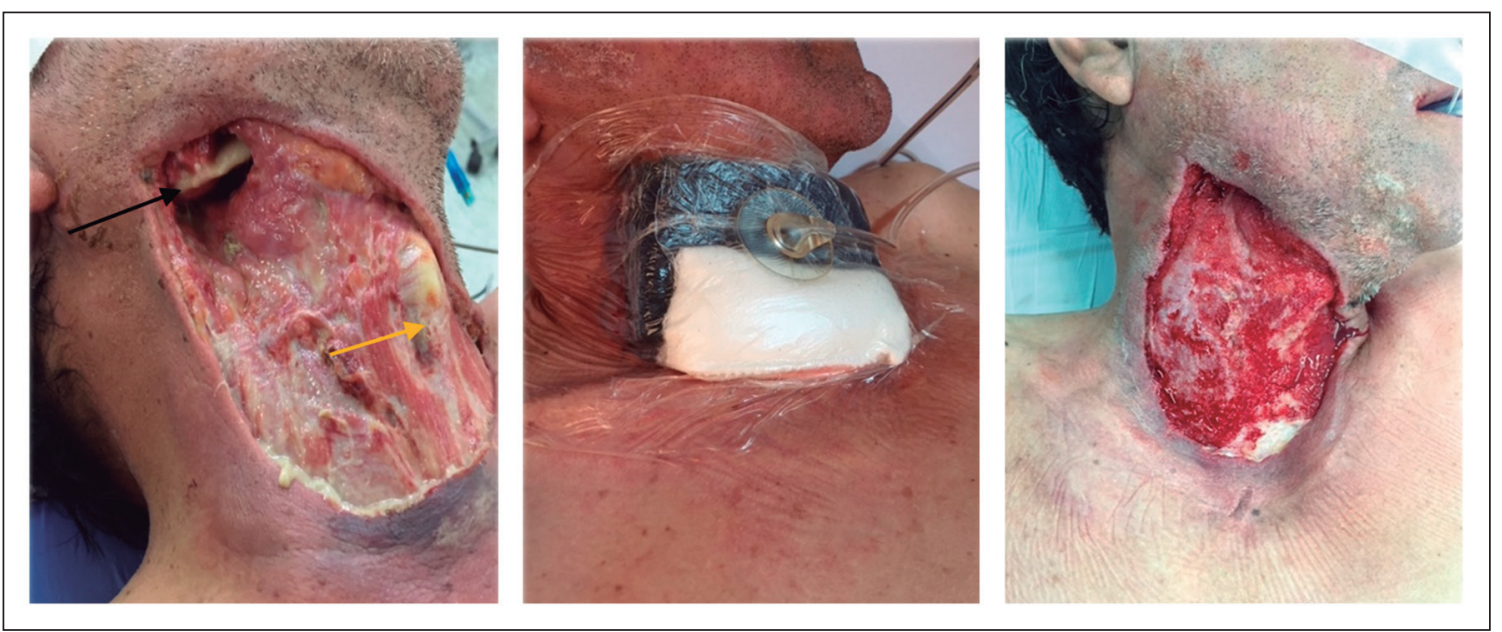

Figura 1. Caso 1. Evolución fotográfica secuencial de la lesión, gran compromiso de músculos superficiales y profundos, con exposición de tráquea (flecha amarilla) y ángulo de la mandíbula (flecha negra). Nótese la extensión hasta tercio superior de hemitórax derecho.

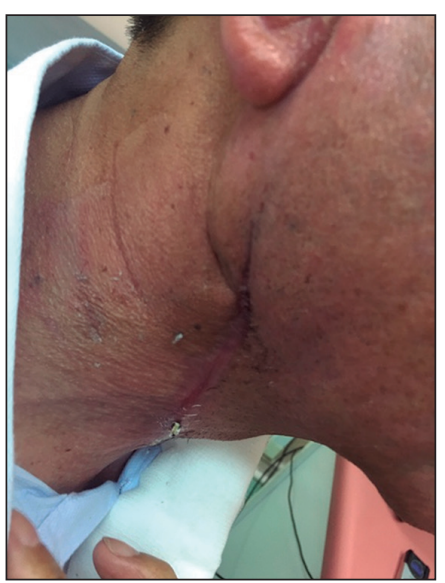

Figura 2. Caso 1: 30 días posterior a egreso. Herida cerrada sin necesidad de afrontamiento con sutura.

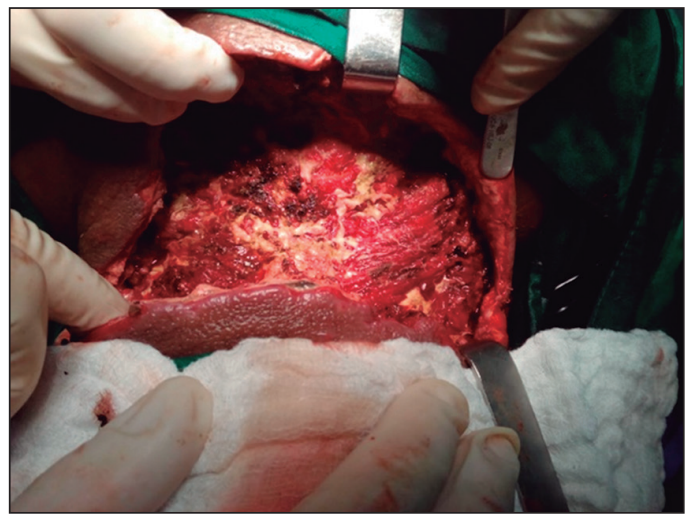

Figura 3. Caso 2. Evidencia del defecto posterior, secundario a $1^{\text {er }}$ aseo en pabellón. 
Staphylococcus aureus, manejado en sala en prono, con sistema VAC y aseos cada $72 \mathrm{~h}$, con egreso a los 31 días y control en consulta externa (Figura 4). 2. Fotografía en consulta externa a los 7 días de alta.
El uso de VAC en el área craneocervical es una parte importante en el manejo posoperatorio de abscesos profundos de cuello, al promover la cicatrización de la herida y la revascularización. Sin embargo, existe muy poca experiencia del uso de sistema VAC en el manejo de heridas infectadas en esta área ${ }^{1-3}$, el uso del VAC resultó útil en el manejo de estos abscesos potencialmente letales.

\section{Responsabilidades éticas}

Protección de personas y animales. Los autores declaran que para esta investigación no se han realizado experimentos en seres humanos ni en animales.

Confidencialidad de los datos. Los autores declaran que en este artículo no aparecen datos de pacientes.

Conflictos de interés: no hay.

\section{Bibliografía}

1. Govea C, Astudillo L, Hermosillo A, Rodríguez J, González S, Fuentes A. Impacto del manejo con cierre asistido al vacío por abscesos profundos del cuello. Cirugía y Cirujanos 2016;84:27581. https://www.researchgate.net/
publication/295395163_Impacto_del_ manejo_con_cierre_asistido_al_vacio_en abscesos profundos de cuello.

2. Thiago Pires Th, Moreira I, Laffitte F, Ricci L, Monteiro CE, Takahiro C, et al. Deep neck abscesses: study of 101 cases. Braz J Otorhinolaryngol. 2017;83(3):3418. https://www.scielo.br/pdf/bjorl/ v83n3/1808-8694-bjorl-83-03-0341.pdf.

3. Benavente $Y$, Palacios R, Silva M, Fuertes M, Gómez-Escolar L. Tratamiento mediante terapia de presión negativa $\mathrm{VAC}^{\circledR}$ de herida infectada tras artrodesis raquídea. Cir. Plást. iberolatinoam. 2011;1:573-76. http://scielo.isciii.es/pdf/ cpil/v37s1/original10.pdf. 